
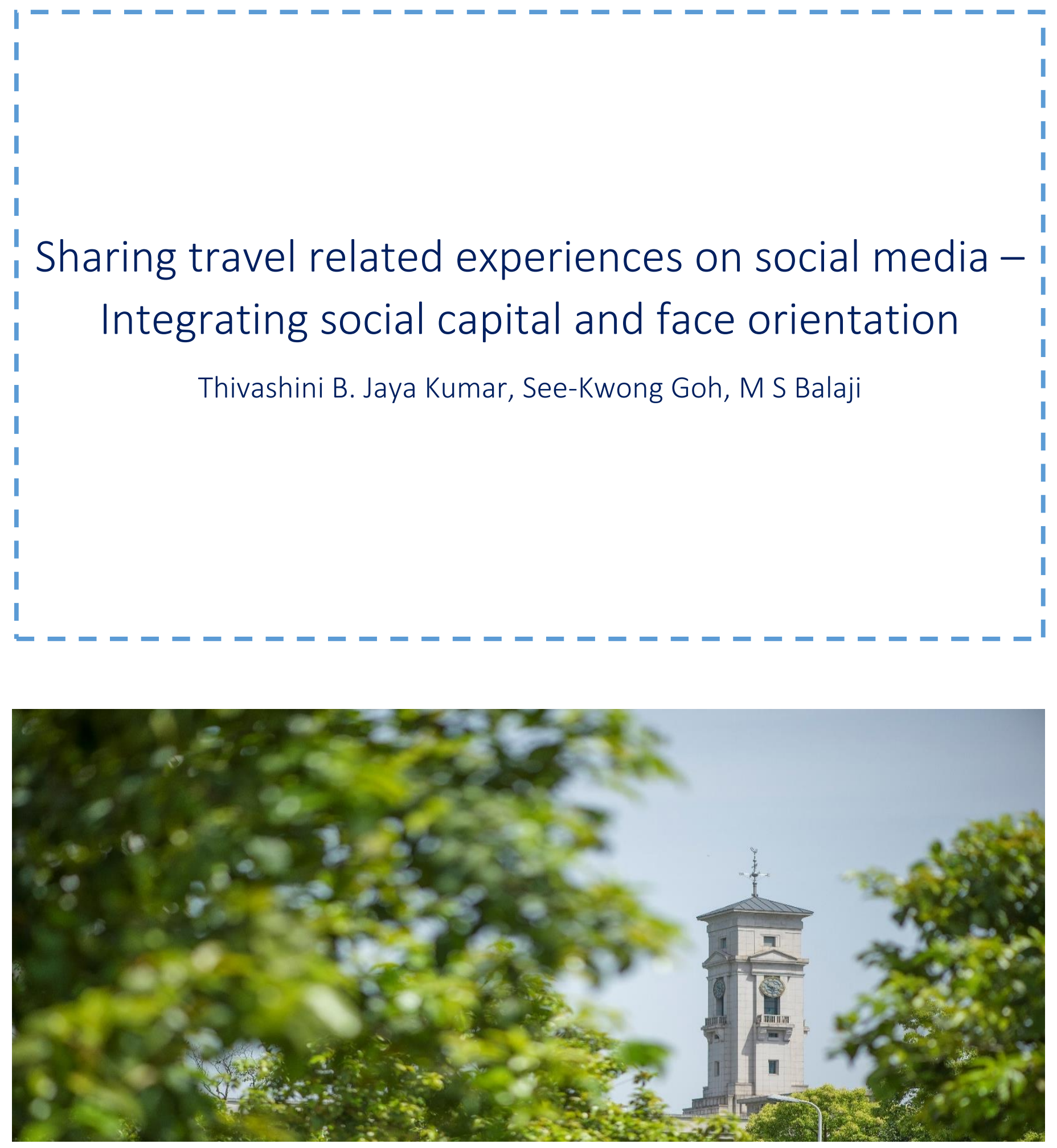
University of Nottingham Ningbo China, 199 Taikang East Road, Ningbo, 315100, Zhejiang, China.

First published 2020

This work is made available under the terms of the Creative Commons Attribution 4.0 International License:

http://creativecommons.org/licenses/by/4.0

The work is licenced to the University of Nottingham Ningbo China under the Global University Publication Licence:

https://www.nottingham.edu.cn/en/library/documents/research/global -university-publications-licence-2.0.pdf 


\title{
Sharing Travel Related Experiences on Social Media - Integrating Social Capital and Face Orientation
}

\author{
Journal of Vacation Marketing
}

Thivashini B. Jaya Kumar

Taylors Business School, Taylors University Malaysia

\author{
Asst. Prof. Dr. Goh See Kwong* \\ Taylors Business School, Taylors University Malaysia \\ No 1, Jalan Taylors, 47500 Subang Jaya, Selangor, Malaysia \\ Email: SeeKwong.Goh@taylors.edu.my \\ *Corresponding author
}

\begin{abstract}
Asst. Prof. Dr. M S Balaji
Nottingham University Business School China, Nottingham University China
\end{abstract}




\title{
Sharing Travel Related Experiences on Social Media - Integrating Social Capital and Face Orientation
}

\begin{abstract}
Tourists can share their travel experiences or related information freely through social media platforms. The purpose of this research is to explore the factors associated with sharing travel related experiences on social media by travellers in the context of social capital theory and personcontext interaction theory. Data were collected among consumers in Malaysia using a structured survey; 423 responses were generated. The findings show that the social capital dimensions (social ties, trust, reciprocity and shared vision) positively impact sharing intention on social media while identification doesn't impact the sharing intention. The results also partially support the hypothesis that protective face orientation negatively influences social capital dimensions and sharing intention while acquisitive face orientation positively influences them. The authors shed light on the construction of social capital dimensions and face orientation and the relative importance of the sharing intention on social media.
\end{abstract}

\section{Keywords}

Social Capital, Face Orientation, Sharing Intention, Social Media, Revisit Intention, Well-being 


\section{Introduction}

The recent emergence of social media has transformed the way we communicate with each other, how we discover product-related information, and more importantly, the way we express our product experiences and opinions with others. Previously, consumers relied on marketer-generated sources such as advertisements or sought advice from family and friends or looked for third-party certificates in their decision-making. Social media is now included among these sources and has become the most preferred mode for searching and exchanging product-related information in some instances (Kapoor et al., 2018).

Social media is considered a tool for facilitating communication mechanisms and bringing people together through sharing content, which is known as user-generated content (Balaji et al., 2015; Michaelidou et al., 2011). The Internet Users Survey (IUS) conducted by the Malaysian Communications and Multimedia Commission (MCMC) provides information on the characteristics and behaviours of Internet users in Malaysia. A recent IUS 2018 reported that the percentage of Internet users in Malaysia continues to rise from $76.9 \%$ in 2016 to $87.4 \%$ in 2018 . Social engagement continues to be the most frequent activity amongst Internet users, with $85.6 \%$ of Malaysian Internet users reportedly having access to social networking sites (MCMC, 2019). The survey also stated that the majority of Internet users relied on the Internet for information seeking and had shared content online via social media. Among those who have shared content online, it was claimed that it was beneficial to the recipients or to raise awareness about an issue (MCMC, 2019). Upon realising both the practicality and opportunity along with recent finding, Tourism Malaysia is initiating the incorporation of social media and utilising digital marketing in promoting the Visit Malaysia 2020 (VM 2020) campaign. 
The development of Internet and social media has not only changed the way people communicate, but also the way people plan their trip and share their travel experience with family and others. Specifically, the proliferation of social media has significantly impacted tourism industry in the way travellers search, access, and utilize tourism information (Law et al., 2014; Oliveria, Araujo, \& Tam, 2020; Ritchie et al., 2011). Social media allows travellers to produce, consume, and distribute travel-related information as well as collaborate with tourism service providers. Furthermore, travellers may share public related travel information as well as private individual travel information on social media. As experiences shared by travellers on social media (traveller UGC) can influence many prospective travellers, it has gained increased interest in recent time from both tourism service providers as well as travellers. While past literature had focused on the impact of social media on tourism industry (Conrady, 2007; Gretzel \& Yoo, 2008), recent studies have focused on understanding the motivations for the creation of traveller UGC, the impact of traveller UGC on prospective travellers attitude and behaviours, and tourism outcomes such as image and choice. The present study seeks to contribute to the later by investigating the motivations for sharing travel experience on social media.

As motivations are key determinants of behaviours (Deci \& Ryan, 1985), an understanding of the factors that determine sharing of travel experience is important. The current literature, however, does not fully explain the factors that motivate travellers to share their travel experience on social media (Wang, Huang, Li, \& Peng, 2016). In particular, given that experience sharing is a complex process that is influenced by many personal and social factors (Kang \& Schuett, 2013; Leung \& Chan, 2003), it is critical to understand the factors that determine intentions to share travel experience on social media platforms. Prior studies suggest that sharing travel experiences on social media platforms supports the development and maintenance of social capital as it helps 
connect with other network members and build social bonds (Belk \& Llamas, 2012). However, prior studies indicate that personal factors may determine the social interactions or how much information is shared with network members (Kim, Kang, \& Lee, 2018; Tsiakali, 2018). Thus, sharing travel experience involves an interplay between personal and social factors. Despite this scant attention is paid in literature on how personal factors determine the access to social resources on social media platforms from sharing travel experience.

The present study addresses this research gap by examining the role of travellers face orientation in the relationship between social capital and travel experience sharing intentions. Face is defined as the travellers cognitive response to social evaluations. While face was originally developed in the Chinese Confucian culture, an individual's concern for image in public is universal. The literature suggests that travellers can engage in behaviours aimed at gaining face (acquisitive) or saving face (protective) (Wang et al., 2016). Protective orientation travellers are vigilant, shy, and keep low profile, who believe that miscommunication or mistakes can cause them lose face. On the contrary, travellers with acquisitive orientation are attention seekers who have a high desire to establish a positive image through self-promotion and ingratiation (Wang et al., 2016). Thus, the decision to share travel experience on social media is a social dilemma. By not sharing travel experience, a traveller can save face from miscommunicating wrong information. On the other hand, a traveller can build his public image by sharing the travel experience with others and build social capital. Given this, an understanding of how a travellers face orientation influences their social capital and resources from sharing travel experience on social media platforms is critical for both practitioners and researchers. 
The present study has two aims: first, to explore how social capital dimensions (structural, relational, and cognitive) influence travellers intentions to share travel experience on social networking sites, and second, to examine the moderating role of face orientation (protective vs. acquisitive). The contributions of the present study to the literature is threefold. First, the present study contributes to literature on motivations for sharing travel experience on social media (Oliveria, Araujo, \& Tam, 2020). Second, the present study contributes to the literature on social capital and experience sharing by examining the role of social capital dimensions on sharing travel experience (Kim \& Shim, 2018). Third, by examining the role of face orientation, the present study contributes to the literature on factors that motivate or hinder sharing travel experience on social media (Chang et al., 2020; Hung, Xiao, \& Yang, 2013).

The following study develops and tests an integrated model of travellers intention to share their travel experiences on social media. Specifically, it integrates social capital and face orientation concepts in developing a research framework for sharing intentions on social media. Information system literature argues that the network of relationships among members on social media could provide the necessary resources to facilitate sharing (Amblee and Bui, 2011; Chu and Choi, 2011; Kasabov, 2015). Thus, the notion of social capital can be utilised to explain why customers might engage in sharing communication on social media. Social capital refers to the sum of assets or resources with a collective value of all networks of relationships (Nahapiet and Ghoshal, 1998). Studies conducted by Chang and Chuang (2011), and Jin et al. (2015), have applied social capital dimensions as a means of investigating how social factors, including social ties, trust and others, influence a user's decisions or actions in connection with social media use for sharing activities. Although previous studies have examined sharing intention on social media for travel related 
experiences (Bilgihan et al., 2016; Kim et al., 2017; Yuan et al., 2016), the effect of social capital dimensions on sharing travel-related experiences on social media has received scant attention.

Secondly this study focuses on the role of face orientation among the three dimensions of social capital and their impact on sharing intention for travel-related experiences on social media. The literature suggests that individuals can have behavioural goals aimed at protecting themselves from losing face, and there are two types of face orientation: protective face orientation (PFO) and acquisitive face orientation (AFO) (Chou, 1996; Ho, 1976). Face is a personal and situational factor that relates to the way individuals engage in interpersonal interaction (Leung and Chan, 2003). Huang et al. (2010) indicate that face is a two-edged sword whereby AFO has a negative impact on the intention to share while PFO has a positive impact. However, Ding (2011) and Wang et al. (2016) indicated that AFO has a negative impact on sharing while PFO does not play a positive role. Face orientation has received less attention, despite its importance for communication, negotiation and social interaction (Ding et al., 2017). Thus, unlike existing studies, the present work integrates social capital theory and person-context interaction theory to explore the effect on individual tourism-sharing intention on social media. This study enhances the understanding of travellers intentions to share their travel experiences on social media by focusing on the technological factor of social capital and individual factor of face-orientation.

The next section of this paper presents a critical examination of the literature and development of the study's hypotheses. This is followed by a description of the research design, data collection methods, and data analysis methods and techniques. Finally, the study results are presented, and theoretical and practical implications are provided. The paper concludes by highlighting emerging conclusions from the study and providing suggestions for future research. 


\section{Literature Review}

\section{Social Capital Theory}

Social capital theory, introduced by Coleman (1988), refers to the resources gathered through relationships among people. This theory has been widely used in the social, organisation, and management domains. Social capital refers to the sum of assets or resources with a collective value of all networks of relationships (Nahapiet and Ghoshal, 1998). The idea is that knowledge and resources are exchanged, work gets done, and value is created through social relationships (Rottman, 2008). Social capital is embedded in relationships between individuals and their connections with their communities. Gu and Wang (2014) stated that social interaction is a necessary feature for the social network system in terms of sharing information and word of mouth.

Past literature suggests that social capital consists of three dimensions, namely, structural, cognitive, and relational. The structural dimension deals with the overall pattern of connection or relationships between individuals. It describes the impersonal configuration of linkages between individuals and the extent to which individuals are connected with one another (Nahapiet and Ghoshal, 1998). The structural dimension includes network ties, network configuration, and appropriable organisation (Nahapiet and Ghoshal, 1998). An individual with specific network ties may access valuable information before others do, obtain referrals, and enhance information value (Zheng et al., 2014).

The relational dimension refers to personal relationships between people that arise from interpersonal contact made through a history of interactions (Nahapiet and Ghoshal, 1998). The relational dimension captures the concepts of trust, norms, obligations, and identification (Nahapiet and Ghoshal, 1998). The relational dimension can affect individual behaviour by 
decreasing communication barriers, enhancing the intention to share and encouraging members to take action and achieve group goals by helping each other (Chang \& Chuang, 2011; Pai \& Tsai, 2016).

The cognitive dimension refers to the shared paradigm and refers to those resources providing shared representations, interpretations, and systems of meaning among parties (Nahapiet and Ghoshal, 1998). The cognitive dimension includes shared codes and language, and shared narratives (Nahapiet and Ghoshal, 1998). The cognitive dimension is articulated as a shared vision predicated on a common language, shared meanings, and an understanding of values and goals among the members of the network as they interact to share information (Chang \& Chuang, 2011). Several studies have adopted the social capital dimension to understand the impact on experience sharing (Chang \& Chuang, 2011; Akhavan \& Hosseihi, 2015), information sharing on supply chain (Lee \& Ha, 2018; Yang \& Li, 2016) and information sharing on social media (Choi \& Scott, 2013; Chung, Nam \& Koo, 2016; Kim, Lee \& Bonn, 2016).

\section{Face Orientation}

According to person-context interaction theory, individuals and the environment or situation are not two separate entities but represent a continuous two-way interaction (Magnusson \& Stattin, 1998). Based on this theory, knowledge sharing on social media is influenced by personal and situational factors. Face is a socio-cultural factor that was initially developed in Chinese Confucian society (Lin, 1936); however, the concept of face is universal in nature (Ho, 1976). Zhang (2011) mentioned that in order to maintain smooth and effective social interactions, individuals involved in the interaction are required to convey minimal acceptable public images of them as well to assist others in maintaining their social identities. According to Ho (1976), the face of an individual continually changes as it can be enhanced or diminished during social interaction. Researchers 
have realised the importance of face during social interaction, but prior research has only examined the effect of face in knowledge sharing in the Chinese context (Huang et al., 2008; 2010; Ding et al., 2011; Wang et al., 2016). Face orientation consists of two dimensions, namely protective face orientation (PFO) and acquisitive face orientation (AFO), which are described according to positive or negative evaluations (Ho, 1976; Wang et al., 2016). PFO is also known as face-gaining and refers to a behavioural orientation that maintains and promotes an individual's positive image and social-esteem from others. By contrast, AFO, also known as face-saving, refers to a behavioural orientation to avoid a negative evaluation and retain social standing in all potentially damaging situations.

\section{Structural Dimension: Social Interaction Ties}

Social interaction ties refer to the network-related social relationships that describe the pattern of linkages in terms of density, hierarchy, and connectivity. Social interaction ties are channels for information and resource flow. Structural dimension reflects the impersonal properties of network relations while social interaction ties represent the basic element of communication networks. Sharing intention is achieved when networks have strong connections and direct ties between their members. Studies have shown that social interaction ties have a positive relationship with sharing intention in social networking sites (Tan, 2013 and Prasetio, 2014) and positively influence the intention of consumers to engage in electronic word-of-mouth (eWOM) on social networks (Wang et al., 2016). 
When consumers perceive social interaction ties as strong, they may be more willing to share information. They feel strong ties are closer and important for each other to share information that can influence each other's decisions (Chu and Kim, 2011). Prasetio (2014) also stated that the level of social interaction ties affects willingness to share information such that the more consumers feel tied to each other, the more likely they are to share information. Studies by Chai and Kim (2011) and Ho et al. (2012) indicate that initiative to share information increases when a close real-life friendship exists on social networking sites. In contrast, when consumers perceive social interaction ties as weak, they tend to share less information. They evaluate that information shared with weak ties will have less influence on their decisions. Chances of exchanging and sharing information exist when there is cooperation between consumers, while in weak ties, cooperation is low, which leads to less information sharing (Tohidinia and Mosakhani, 2010). Further, consumers with strong ties share credible information with others more frequently, while consumers with weak ties are likely to share narrative information (Wang et al., 2016). It is expected that sharing intention is high when social interaction ties are strong and vice-versa. Thus, we hypothesise that:

H1: Social interaction ties positively impact sharing intentions on social media.

\section{Relational Dimension: Trust, Identification and Norm of Reciprocity}

\section{$\underline{\text { Trust }}$}

Trust is known as a set of specific beliefs dealing primarily with integrity, which refers to an individual's expectation that members in a group will follow a generally accepted set of values, norms, and principles. Trust is an enabler for social exchange and cooperation, and it opens up 
people for knowledge sharing. Previous studies have found that trust is significantly related to information exchange and knowledge sharing (Chai et al., 2011; Gu and Wang, 2014) and electronic word of mouth (Choi and Scott, 2013; Chu and Kim, 2011).

When relationships are trustworthy, members of the social network are more willing to share their information since they have no fear of being exploited by the other members (Chang and Chuang, 2010). Meanwhile, when relationships are low on trust, members in the social network tend to share less information. Cao et al. (2013) explained that trust is a stronger predictor of information sharing, because social media includes loosely connected individuals with different backgrounds and fewer interactions and thus, removing communication barriers is important to further information sharing. According to Cao et al. (2013), trust allows consumers to evaluate the source and value of information and justify their decision to share their information. Chu and Kim (2011) stated that a consumer's willingness to rely on their social connections is enhanced due to perceived reliability and trustworthiness. Besides, trust also promotes the use of information since it enhances the credibility of the information. Chang and Chuang (2010) found that trust has a positive effect on the quality of knowledge sharing and does not have an effect on the quantity of knowledge sharing. It is expected that consumers share more information when trust is high and vice-versa. Thus, we hypothesise that:

$\mathrm{H} 2$ : Trust positively impacts sharing intentions on social media.

\section{$\underline{\text { Identification }}$}

Identification is one's conception of self in terms of the defining feature of the self-inclusive social category, the process whereby individuals see themselves belonging to a set of people or group. It 
also includes a member's sense of belongingness and positive feelings towards a social network and explains the readiness to remain an active member of the network. It reflects individuals' efforts to express and present themselves to others, and it enhances the degree of knowledge contribution (sharing of information, knowledge creation, and learning).

Choi and Scott (2013) found a positive relationship between identification and electronic word-ofmouth (eWOM) quality and information sharing. When consumers perceive high identification, they may be more willing to share information. Consumers perceive opportunities for exchanging information with others as well enhancing the actual frequency of cooperation when identification is high. Another study by Chang and Chuang (2010) also showed that identification had a significant and positive effect on knowledge sharing. They also stated that users on social media are based on existing networks or profiles with similar characteristics between them, which in turn increases identification. Reliability of a consumer's opinions or information increases when identification increases.

In contrast, when consumers perceive low identification, they tend to share less information. Valuable knowledge is embedded in individuals and people would not contribute their knowledge unless another person is recognised as their group-mate and the contribution is conducive to their welfare. The perception of social unity and togetherness of the community will elevate people's activeness to share and increase the depth and breadth of shared knowledge. It is expected that consumers share more information when identification is high and vice-versa. Thus, we hypothesise that:

H3: Identification positively impacts sharing intention on social media. 


\section{Norm of reciprocity}

Reciprocity norm refers to knowledge exchange that is mutual and perceived by both parties as fair. It is expected that knowledge sharing in the social network by a member is induced by the expectation that others would reciprocate their requests when required. If the invested efforts in knowledge sharing can be reciprocated, members are motivated to contribute more. Prior studies have shown that the reciprocity norm has a significant impact on consumer information-sharing behaviour (Chang and Chuang, 2011; Liu, Cheung and Lee, 2016).

When consumers perceive the reciprocity norm as high, they may be more willing to share information. Consumers who receive appreciation from others for their contribution become even more motivated to continue contributing (Liu, Cheung and Lee, 2016). When consumers perceive a low reciprocity norm, they tend to share less information. Consumer motivation to share information decreases when they receive a lower response from others.

When a consumer provides his/her opinions or information to others, consumers who receive it are indebted to give worthy feedback to the information giver (Hung, Lai and Chang, 2011). As mentioned by Pai and Tsai (2016), this enhances mutual interaction as consumers who receive responses are willing to interact even more with others and share more information. Furthermore, information feedback and mutual benefits in the future exist when consumers reciprocate comments from other consumers (Yang and Li, 2016). It is expected that consumers share more information when the reciprocity norm is high. Thus, we hypothesise that:

H4: Norm of reciprocity positively impacts sharing intentions on social media. 


\section{Cognitive Dimension: Shared Language}

Shared language is a tool for the evaluation of the benefits of knowledge exchange. Mutual knowledge can increase the likelihood of understanding between members because it allows them to formulate their knowledge as a result of knowing what the receiver does and does not know (Chang and Chuang, 2010). Studies have shown that shared language has a significant positive relationship with knowledge sharing (Cao et al., 2013; Prasetio, 2014) and eWOM (Choi and Scott, 2013).

When consumers perceive shared language as high, they may be more willing to share information. Consumers are willing to share their knowledge when they have the same vision as others (Prasetio, 2014). Consumers feel that shared language enhances their ability to access information as well as to share information as it reduces both encoding and decoding efforts (Cao et al., 2013). Besides, consumers also think communication efficiency and mutual understanding is enhanced by shared set of vocabulary and terms.

In contrast, when consumers perceive shared language as low, they tend to share less information. Consumers feel individuals who do not share a common language understand each other less, and this might result in misunderstandings in communication (Liu, Cheung, and Lee, 2016). Further, Chang and Chuang (2010) stated that shared language motivates the network members to indulge in knowledge exchange activities actively and enhances the quality of knowledge shared in the network. It is therefore expected that consumers share more information when shared language is high and vice-versa. Thus, we hypothesise that:

H5: Shared language positively impacts sharing intentions on social media. 


\section{Revisit Intention}

Revisit intention refers to the individual's judgment about visiting a designated service from the same company again, considering their current situation and likely circumstances (Hellier et al., 2003). According to Wang et al. (2012) tourists' revisit intention has been important in the determination of tourist destination. Higher revisit intention was discovered when travellers were attached to an organisation social media page (Leung and Bai, 2013). Wang and Wu (2011) found that higher involvement of travellers induced higher intention to revisit a museum. An individual's higher involvement on the Internet brought about a higher level of intention to purchase travel products through the Internet (Moital et al., 2009). It is expected that consumer revisit intention depends on sharing intention on social media. Thus, we hypothesise that:

H6: Sharing intentions on social media have a positive impact on revisit intention.

\section{Well-being}

Subjective well-being refers to hedonic perspectives, such as positive affect (happiness), lack of negative affect, and life satisfaction (Ryan and Deci, 2001). In short, well-being is gained when some state, such as a goal, has been achieved. Prior research has examined the relationship between the use of SNSs and individuals' well-being (Ellison, Steinfield and Lampe, 2007; Valenzuela, Park \& Kee, 2009). In this study, subjective well-being is defined as an individual's own assessment of their happiness and satisfaction with their social life on social media (Chiu et al., 2013). According to self-determination theory, individuals are self-determining and intrinsically motivated to continue using social media and saying positive words about it when they feel happy about doing so and vice-versa. Thus, we hypothesise that:

H7: Sharing intentions on social media have a positive impact on well-being. 
Face Orientation: Protective Face Orientation (PFO) and Acquisitive Face Orientation (AFO)

\section{Protective face orientation (PFO)}

Protective face orientation (PFO) refers to the fact that some individuals with behavioural goals aim to protect themselves from losing face (Wang et al., 2016). Individuals with high PFO are modest, cautious, focused on getting along with others, and inclined to keep a low profile (Chou, 1996). PFO can act as a barrier preventing tourists from sharing knowledge or information about their travel experiences with others on social media. According to Ardichvili et al. (2006), individuals with high PFO will never publicly disclose their weaknesses or misunderstandings because it could cause them to lose face and be embarrassed or even disrespected by others.

Wang et al. (2016) showed that PFO weakens the impact on knowledge sharing, especially among those who have higher PFO. Besides, Ding et al.'s (2017) study also showed that PFO is a negative social orientation. The authors further state that PFO is negatively motivated by psychological factors because of the desire to avoid negative evaluation as well as to retain social standing in all potentially damaging situations. Thus, we hypothesise that:

H8: Protective face orientation negatively moderates the relationship between social capital dimensions and sharing intention on social media.

H8a: The relationship between social interaction ties and sharing intention on social media is weaker for tourists with high PFO.

H8b: The relationship between trust and sharing intention on social media is weaker for tourists with high PFO. 
H8c: The relationship between identification and sharing intention on social media is weaker for tourists with high PFO.

H8d: The relationship between reciprocity and sharing intention on social media is weaker for tourists with high PFO.

H8e: The relationship between shared language and sharing intention on social media is weaker for tourists with high PFO.

\section{Acquisitive face orientation (AFO)}

Acquisitive face orientation (AFO) is characterised by attention-seeking through ingratiation, selfpromotion, and exemplification (Wang et al., 2016). According to Chou (1996), individuals with a high level of AFO desire to establish a positive public image or favourable reputation in front of others. In other words, tourists with high AFO believe that posting their experience will raise their image or status among others. Given the above considerations, it can be inferred that travellers with high AFO should exhibit stronger sharing intention and more sharing behaviour. Prior studies have proposed that AFO has a positive effect on various behaviours (Huang et al., 2008; Leung et al., 2014; Zhang, Cao, \& Grigoriou, 2011); however, studies by Ardichvili et al. (2006), Ding et al. (2017) and Wang et al. (2016) did not observe a positive effect of AFO on knowledge sharing. Hence, Wang et al. (2016), in their study, argued that even individuals with high AFO are conscious of gaining face; they are not willing to share their travel experiences. Thus, we hypothesise that: 
H9: Acquisitive face orientation positively moderates the relationship between social capital dimensions and sharing intention on social media.

H9a: The relationship between social interaction ties and sharing intention on social media is stronger for tourists with high AFO.

H9b: The relationship between trust and sharing intention on social media is stronger for tourists with high AFO.

H9c: The relationship between identification and sharing intention on social media is stronger for tourists with high AFO.

H9d: The relationship between reciprocity and sharing intention on social media is stronger for tourists with high AFO.

H9e: The relationship between shared language and sharing intention on social media is stronger for tourists with high AFO.

Based on the review of the literature and hypotheses developed, the following model is proposed (see Fig. 1).

[Figure 1 near here] 


\section{Methodology}

The data were collected through a survey using a structured questionnaire from respondents in Malaysia. The reason is that, in recent years, Malaysia has experienced an increase in Internet usage, especially on social media. As a result, Tourism Malaysia has focused on a social media campaign to promote Malaysia 2020. It is important to understand Malaysian tourists' sharing behaviour of their travel experiences on social media, as such understanding will further help Tourism Malaysia to develop effective social media strategies. The respondents were chosen from a Malaysian population using a purposive sampling technique. This technique was used to select respondents who had travelled recently and were active on a social media platform. Table 1 provides demographic statistics of the sample data. A total of 423 respondents were collected, 207 were for a positive travel experience and 216 were for a negative travel experience. This sample size was adequate to represent the population in Malaysia at a 95\% confidence level, according to Krejcie \& Morgan's (1970) sample table.

The questionnaire encompassed six demographic (gender, age, education level, occupation) items, seven SNS usage items, five tourism-related activity participation items, and a total of 42 items for nine factors. Items used to measure study constructs were based on indicators from prior research studies. Social ties, trust, reciprocity, identification, and shared vision and language, which are sub-dimensions of structural, relational, and cognitive dimensions of social capital, were measured using 19 items suggested by Chang and Chuang (2011), Chu and Kim (2011), Cao et al. (2013), and Choi and Scott (2013). Four items for sharing intention on social media were taken from Chung et al.’s (2016) and Lee et al.'s (2014) studies. 
The variable revisit intention has been measured using three items developed by Kim and Cho (2013) and Liu and Lee (2016). Four items for the well-being were adapted from Chiu et al. (2013) study. Lastly, 12 items for PFO and AFO, which are sub-dimensions of face orientation were adopted from Wang et al. (2016). All of the items were rated on a 7-point Likert-type scale in which 1 represented 'strongly disagree' and 7 represented 'strongly agree'. To reduce potentially confounding effects, this study controlled for several common background variables known to impact user's intention to share travel-related experiences. In the present study, we controlled for respondents' gender, age, education, and occupation.

From the sample, $63.6 \%$ of the respondents $(n=269)$ were females and the majority of the respondents $(75.9 \%)$ were aged between 19 and 29 years. In terms of educational background, 81.3\% had a bachelor's degree. Regarding occupation, $64.8 .5 \%(n=274)$ were students, $33.1 \%$ $(n=140)$ were employed in private and public firms. As per the data sample, $68.3 \%$ of the respondents chose Facebook as the most used SNS while Instagram was the second most used SNS with $23.6 \%$. Table 1 reports the description of the final sample.

\section{[Table 1 near here]}

In order to analyse the data, a partial least squares (PLS) approach to structural equation modelling (SEM) was used to test the various relationships. Specifically, the SmartPLS 3.0 program was used to estimate the model's parameters (Ringle et al., 2015). SEM is a 'quasi-standard' in marketing research, which enables researchers to test complete theories and concepts (inner or structural model and outer or measurement model) (Hair et al., 2011). 
In addition, PLS path modelling becomes an essential method in empirical research (Rezaei, 2018; Sarstedt et al., 2011). PLS-SEM is a "causal modelling approach aimed at maximizing the explained variance of the endogenous latent constructs' (Hair et al., 2011, p. 139). According to Hair et al. (2011), PLS-SEM does not rely on normality assumptions, and it is a component-based approach that can be used to predict key target variables. PLS-SEM is preferred over covariancebased SEM (CB-SEM) as the model is complex and if we assume that measured variance is useful for explanation/ prediction of structural relationships (Hair et al., 2013). PLS-SEM is, however, advantageous compared to CB-SEM when analysing predictive research models that are in the stages of theory development (Gimbert et al., 2010; Rezaei, 2018) and the statistical objective in PLS-SEM is to maximise the explained variance of the endogenous latent constructs (Hair et al., 2013). Therefore, PLS-SEM was found suitable in this study to conduct and assess measurement and structural models and test the proposed research arguments using SmartPLS software developed by Ringle et al. (2015).

First, confirmatory factor analysis (CFA) was carried out to assess the measurement model. Structural Equation Modelling (SEM) was performed to assess the hypothesised relationships. Common method variance (CMV) threatens the reliability of the findings and it occurs when the data are obtained from a single source survey (Reio, 2010). We addressed this issue (CMV) by using Harman's single factor test (Podsakoff et al., 2003) and Lindell and Whitney's (2001) Marker Variable method. According to Harman's single factor test, an exploratory factor analysis was performed. Results showed the first factor explained $40.22 \%$ of the total variance, lower than the suggested 50\% threshold. These tests did not indicate a single factor structure that accounted for the majority of the variances, suggesting common method bias is not a major issue in this study. 
Furthermore, based on the method proposed by Lindell and Whitney (2001), a marker variable was introduced in the PLS model to assess the common method bias by determining the correlation between the marker variable and the latent variables. The correlations between the latent variables and the marker variable was less than 0.3. This suggests that common method bias is not a problem in this study.

\section{Results}

The two-step modelling approach recommended by Anderson and Gerbing (1988) was used to assess the constructs' measurement properties (the outer model) and the structural (the inner) model. Measurement properties were examined first to assess reliability and validity, after which the structural model was estimated. The structural model was used to test hypotheses H1-H9.

\section{Confirmatory factor analysis (CFA) \& constructs' measurement properties}

At first, confirmatory factor analysis (CFA) was conducted to test the validity of the model. Initial analysis revealed that five loadings, namely social interaction ties (ST3), identification (ID4), revisit intention (RV1), protective face orientation (PFO3) and acquisitive face orientation (AF01) were not satisfactory (less than 0.6) and were dropped from further analysis. Following this, the CFA shows that the item loadings on their respective latent factor were satisfactory (greater than $0.7)$ and statistically significant $(\mathrm{p}<0.01)$ (see Table 2$)$.

Cronbach's alpha and composite reliability test were used to test the reliability of study constructs. As shown in Table 3, the Cronbach's alpha and composite reliability values were more than the recommended threshold level of 0.7 . Thus, the measurement scales were internally consistent and reliable. 
An evaluation of the factor item loadings and average variance extracted (AVE) was undertaken to check the convergent validity of the construct measures. As shown in Table 3, the AVE values greater than the 0.50 level, confirming the convergent validity of the measures (Fornell and Larcker 1981; Hair et al., 2017). Further, discriminant validity was inspected by comparing the shared variance between factors with the square root of the AVE (Fornell and Larcker, 1981). Table 4 confirms that the first was lower than the latter. Thus, discriminant validity was achieved. Further, multicollinearity was not present in the findings as variance inflation factors (VIFs) were all beneath the cut-off value of 5.00 .

\author{
[Table 2 near here] \\ [Table 3 near here] \\ [Table 4 near here]
}

\title{
The Structural Model
}

A bootstrapping procedure with 5000 resamples was used to estimate the paths' significance (Hair et al., 2011) in the structural model. The estimated model was evaluated using a number of indices, including R2 values, path coefficients, bootstrapping critical ratios, and a redundancy analysis. The usefulness of the model was established by combining predictive relevance and the strength of the path coefficients. The variance explained by the model in terms of $\mathrm{R} 2$ was 0.589 for intention to share, 0.039 for revisit intention and 0.599 for wellbeing. Hence, the R2 for intention to share and well-being can be classified as moderate while R2 for revisit intention was weak. For the completed model, we obtained a SRMR value of 0.071 and NFI value of 0.658 . SRMR values less than 0.10 or of 0.08 (Hu and Bentler, 1999) are considered a good fit. The results suggest the model was a good fit to the data. 
The individual path coefficients of the PLS structural model can be interpreted as standardised beta coefficients of OLS regressions. The results of the structural model analysis are shown in Figure 2 and presented in Table 5 as well an overview of results in Table 5.

[Figure 2 here]

[Table 5 near here]

[Table 6 near here]

H1 predicted that social interaction ties exert a positive direct influence on intentions to share travel experiences on social media and this was supported $(\beta=0.161, \mathrm{p}<0.05)$. Trust demonstrated a significant association with travel experience sharing intentions on social media $(\beta=0.121, \mathrm{p}<$ 0.05). This supports H2. Hypothesis 3 was supported as reciprocity norm demonstrated a significant positive effect on sharing intentions for travel experiences $(\beta=0.330, p<0.05)$. H4 predicted that identification exerts a positive direct influence on sharing intention on social media. This was not supported $(\beta=0.003, \mathrm{p}=0.995)$. H5 proposed that shared value exerts a positive direct influence on sharing intentions for travel experiences on social media. The results support the positive significant relationship between shared value and sharing intentions $(\beta=0.209, \mathrm{p}<$ 0.05). The results for H6, which suggest a positive relationship between sharing intention on social media and revisit intention, was supported $(\beta=0.167, \mathrm{p}<0.05)$. Lastly, $\mathrm{H} 7$ that predicted a positive relationship between sharing intention on social media and well-being and this was also supported $(\beta=0.773, p<0.05)$. In summary, Hypotheses $1,2,3,5,6$ and 7 were accepted. 
An assessment of indirect impact was performed to test the mediation effect. The results are given in Table 5. As observed, all social capital dimensions excluding identification had significant indirect effect on revisit intention and well-being. Social capital dimensions of social interaction ties $(\beta=0.125, \mathrm{p}<0.05)$, trust $(\beta=0.093, \mathrm{p}<0.05)$, reciprocity $(\beta=0.255, \mathrm{p}<0.05)$ and shared value $(\beta=0.162, \mathrm{p}<0.05)$ showed an indirect effect on well-being excluding identification $(\beta=$ $0.002, p=0.995)$ which had no significant indirect effect. On the other hand, social capital dimensions of social interaction ties $(\beta=0.029, \mathrm{p}<0.05)$, trust $(\beta=0.074, \mathrm{p}<0.05)$, reciprocity $(\beta=0.059, \mathrm{p}<0.05)$ and shared value $(\beta=0.048, \mathrm{p}<0.05)$ showed an indirect effect on revisit intention excluding identification $(\beta=0.001, p=0.938)$ which had no significant indirect effect.

\section{Moderation Analysis}

H8 predicted a moderating relationship between protective face orientation and social capital dimensions on intention to share travel experiences on social media. As shown in Table 5, the moderating effect of social interaction ties and PFO had a negative significant impact on sharing intention on social media $(\beta=-0.347, p<0.05)$. The results for Hypotheses $8 b$ to $8 \mathrm{e}$ were not supported as the moderation effect of PFO between the social capital dimensions and sharing intentions on social media were not significant. $\mathrm{H} 9$, which proposed the moderating relationship between AFO and sharing intention on social media, was partially supported. H9a was supported as the relationship between social interaction ties and sharing intention on social media was significant for AFO $(\beta=0.353, p<0.05)$. However, Hypotheses $9 \mathrm{~b}$ to $9 \mathrm{e}$ were not supported as the moderation effect of AFO between social capital dimensions and sharing intention on social media were not significant. 


\section{Discussion}

This study integrates social capital theory and person-context interaction theory to explore the effect on individual tourism-sharing intention on social media. More specifically, the research clarified the influence of social capital dimensions (social ties, trust, reciprocity, identification, and shared value) and face orientation (protective face orientation and acquisitive face orientation) on the intention to share travel-related experiences on social media. The effect of consumer intention to share travel-related experience on social media was examined via nine hypotheses. The findings of this study provide valuable insights about customers' sharing intention on social media.

The present study indicates that structural, relational, and cognitive factors are dimensions of social capital. Social ties contributed positively to the intention to share travel-related experiences on social media. This result support previous findings that suggest a positive effect of social ties and sharing information (Chai and Kim, 2011; Ho et al., 2012; Wang et al., 2016). Such findings indicate that their social interaction ties drive the customer's knowledge or information sharing on social media. This further explains that customers feel closer and more important to each other in terms of sharing information when social ties are strong. Trust and reciprocity enhance the intention to share travel-related experiences on social media. The results suggest that consumers form intentions to share their travel experiences based on trust with social members and reciprocity they receive from members. These results support previous findings that suggest a positive effect of trust (Choi and Scott, 2013; Chu and Kim, 2011; Gu and Wang, 2014) and reciprocity (Chang and Chuang, 2011; Liu et al., 2016) on sharing information. Customers are more willing to share their travel experiences when relationships are high concerning trust because they have no fear of being exploited by others. 
On the other hand, customers are more willing and motivated to share information when reciprocity norm is high because they receive appreciation from others for their contribution.

Shared value also enhances the intention to share travel-related experiences on social media. These results support previous findings that suggest a positive effect of shared value and information sharing (Cao et al., 2013; Choi and Scott, 2013; Prasetio, 2014). Shared value or language enhances their ability to access information as well to share information as it reduces both encoding and decoding efforts (Cao et al., 2013). Customers feel members who share common language and value, understand each other more, and might not end up in misunderstandings of communication. Although all factors from three dimensions showed significant results, identification was not statistically significant. This finding contradicts research findings within the existing literature, where identification is a necessary foundation for knowledge sharing (Chang and Chuang, 2010; Choi and Scott, 2013). However, a study by Yu et al. (2010) showed that identification was not a significant factor that influences knowledge-sharing behaviour. This result is further explained by the fact that members in social media primarily viewed their community as an informational and social universe, rather than as a commercial entity. Identification is weak within this community because of alterable online personalities and social roles. The results extend the current knowledge to the fundamental social capital dimensions that influence the intention to share travel-related experiences on social media. 
Prior evidence suggests that higher revisit intention (Leung and Bai, 2013) and well-being (Chiu et al., 2013) were discovered as travellers became attached to social media experience sharing. Thus, this study also indicates that intention to share travel-related experiences on social media influences revisits intention as well as an individual's well-being. This finding is consistent with the previous literature by showing that in a consumer behaviour context, the higher consumers' intention to share information is, the higher the revisit intention (Leung and Bai, 2013; Moital et al., 2009; Wang and Wu 2011) and level of well-being (Chiu et al., 2013; Ellison et al., 2007; Valenzuela et al., 2009).

Finally, this study indicates that face orientation moderates the relationship between social capital dimensions and intention to share travel-related experiences on social media. The result shows that PFO and AFO are only significant for the structural dimension - social ties. These results are supported by a previous study done by Ding et al. (2017) that shows that PFO is a negative social orientation while AFO is the positive social orientation (Leung et al., 2014). This result is explained by the fact that opinion leaders would feel confident in their ability to make any individual product choice. Since opinion leaders have high levels of product expertise, they conduct little external search for information. AFO did not have a significant effect on the relational and cognitive dimensions. This corroborates the findings from Ardichvili et al. (2006), Ding et al. (2017) and Wang et al. (2016). It also further explains that even with high AFO, individuals are conscious of gaining face but they are not willing to share their travel experiences. 


\section{Theoretical and Practical Implications}

From a theoretical perspective, this study enriches the current literature on influential factors that determine the tourists' intentions to share their travel experiences on social media. We do this by adopting social capital theory and person-context interaction theory. Notably, the theoretical relationships were empirically supported. The present study successfully confirmed the factors that influenced tourists' intention to share travel-related experiences on social media. Most importantly, the findings emphasise the dimensions of social capital and face orientation on attitudinal and behavioural intention. The results of the present study might be considered one of the emerging attempts to empirically investigate tourists' intention to share travel-related experiences on social media, especially in the Malaysian context.

Regarding the practical contribution, the findings of the present study provide insights on tourists' behaviour of sharing their travel experiences on social media. Social media is essential to effectively reach consumers who favour the use of technology-based and internet-based tools. Travel companies need to understand the influential role of social media in tourism as they relate to driving tourists' decisions by informing and inspiring others. Travelers use social media to plan their vacations, and they trust the recommendations and suggestions of their virtual network. According to Law et al. (2015), users communicate the messages to others in social media marketing, which is different from traditional marketing where the company directly sends marketing messages to their customers. Thus, it is important to understand information-sharing behaviours, which are a powerful asset to a business. Industry players must also be aware of the power of eWOM. When there is a positive feedback/ comment regarding the tourism destination, it will spread rapidly, and vice versa for negative feedback. 
Thus, eWOM is of utmost importance as the feedback may be constructive as well as destructive to the business. Players, who use social media as a communication tool with customers, need to persuade customers to share their experiences. By encouraging their customers to share their tourism-related opinions, reviews, and experiences, it helps the firm to improve its service quality as well as to attract new customers and retain their existing customers. Besides that, the findings also help managers to understand the process by which social capital contributes to information sharing. Firms must engage in social interaction with their customers in order to receive feedback.

\section{Limitations and Future Research}

The present study has several limitations. It should be noted that this research was conducted in the Malaysian setting, and hence, the findings of the study may not represent respondents from other geographical areas. Therefore, there is a need to replicate this kind of research in other geographical settings in order to enrich the literature. Future study may be expanded to a broader geographical area to investigate the differences between the findings established in other geographical locations. Besides, a cross-sectional approach was employed in the present study, in which the data were collected at a single point of time (i.e., in a month). Consequently, it is also recommended to employ a longitudinal study in future research. Apart from that, this study did not consider the role of personality and psychological traits as a moderator for intention to share travelrelated experiences on social media. Therefore, future research looking into other possible moderators to obtain a comprehensive understanding of the drivers of behavioural intention is deemed necessary. 


\section{Conclusion}

Overall, the proposed model of the present study shed some light on enhancing the sustainability of the Malaysian tourism industry. From the outcomes of this study, it is evident that the study has provided several significant and useful contributions to consumer behaviour literature, especially in the context of tourism. This study contributes both theoretical and practical implications by identifying the importance of social capital dimensions in influencing sharing travel-related experiences on social media. 


\section{Reference List}

Akhavan P and Hosseini SM (2015) Determinants of Knowledge Sharing in Knowledge Networks: A Social Capital Perspective. The IUO Journal of Knowledge Management XIII(1): 7-24.

Amblee N and Bui T (2014) Harnessing the Influence of Social Proof in Online Shopping: The Effect of Electronic Word of Mouth on Sales of Digital Microproducts. International Journal of Electronic Commerce 16(2): 91-114.

Anderson JC and Gerbing DW (1988) Structural equation modeling in practice: A review and recommended two-step approach. Psychological Bulletin 103(3): 411-423.

Ardichvili A, Maurer M, Li W, Wenting T and Stuedemann R (2006) Cultural influences on knowledge sharing through online communities of practice. Journal of Knowledge Management 10: 94-107.

Balaji MS, Roy SK and Lassar WM (2017) Language divergence in service encounters: Revisiting its influence on word-of-mouth. Journal of Business Research 72: 210-213.

Bharati P, Zhang W and Chaudhury A (2015) Better knowledge with social media? Exploring the roles of social capital and organizational knowledge management. Journal of Knowledge Management 19: 456-475.

Bilgihan A, Barreda A, Okumus F and Nusair K (2016) Consumer perception of knowledgesharing in travel-related Online Social Networks. Tourism Management 52: 287-296.

Bilgihan A, Peng C and Kandampully J. (2014) Generation Y's dining information seeking and sharing behavior on social networking sites. International Journal of Contemporary Hospitality Management 26(3): 349-366.

Cao X, Guo X, Liu H, et al. (2013) The role of social media in supporting knowledge integration: A social capital analysis. Information Systems Frontiers 17(2): 351-362.

Chai S and Kim M (2010) What makes bloggers share knowledge? An investigation on the role of trust. International Journal of Information Management 30(5): 408-415.

Chang HH and Chuang SS (2011) Social capital and individual motivations on knowledge sharing: Participant involvement as a moderator. Information \& Management 48(1): 9-18.

Chang IY (2018) The Influence of eWOM Source Credibility and Product Involvement on Travel Product Purchasing Intention of Malaysian Chinese. KnE Social Sciences 2018: 15821598. 
Chang, Y., Hou, R. J., Wang, K., Cui, A. P., \& Zhang, C. B. (2020). Effects of intrinsic and extrinsic motivation on social loafing in online travel communities. Computers in Human Behavior, 106360.

Chen CJ and Hung SW (2010) To give or to receive? Factors influencing members' knowledge sharing and community promotion in professional virtual communities. Information \& Management 47(4): 226-236.

Chiu CM, Cheng HL, Huang HY and Chen CF (2013) Exploring individuals' subjective wellbeing and loyalty towards social network sites from the perspective of network externalities: The Facebook case. International Journal of Information Management 33(3): 539-552.

Choi J and Scott J (2013) Electronic Word of Mouth and Knowledge Sharing on Social Network Sites: A Social Capital Perspective. Journal of theoretical and applied electronic commerce research 8(1): 11-12.

Chou ML (1997) Protective and acquisitive face orientation: A person by situation approach to face dynamic in social interaction. Doctoral dissertation, The University of Hong Kong, China.

Chu SC and Choi SM (2011) Electronic Word-of-Mouth in Social Networking Sites: A CrossCultural Study of the United States and China. Journal of Global Marketing 24(3): 263281.

Chu SC and Kim Y (2015) Determinants of consumer engagement in electronic word-of-mouth (eWOM) in social networking sites. International Journal of Advertising 30(1): 47-75.

Chung N, Nam K and Koo C (2016) Examining information sharing in social networking communities: Applying theories of social capital and attachment. Telematics and Informatics 33(1): 77-91.

Coleman JS (1988) Social capital in the creation of human capital. American journal of sociology. 94: S95-S120.

Ding G, Liu H, Huang Q, Gu J (2017) Moderating effects of guanxi and face on the relationship between psychological motivation and knowledge-sharing in China. Journal of Knowledge Management 21(5): 1077-1097.

Ellison NB, Steinfield C and Lampe C (2007) The Benefits of Facebook "Friends": Social Capital and College Students' Use of Online Social Network Sites. Journal of Computer-Mediated 
Communication 12(4): 1143-1168.

Fornell C and Larcker DF (1981) Evaluating Structural Equation Models with Unobservable Variables and Measurement Error. Journal of marketing research 18(1): 39-50.

Gimbert X, Bisbe J and Mendoza X (2010). The role of performance measurement systems in strategy formulation processes. Long Range Planning, 43(4): 477-497.

Gu C and Wang S (2012) Empirical Study on Social Media Marketing Based on Sina Microblog. In: 2012 Second International Conference on Business Computing and Global Informatization, Shanghai, China, 12-14 October 2012, pp. 537-540. Shanghai: IEEE.

Hair JF, Ringle CM and Sarstedt M (2011) PLS-SEM: Indeed a Silver Bullet. Journal of Marketing Theory and Practice 19(2): 139-151.

Hair JF, Ringle CM and Sarstedt M (2013) Partial least squares structural equation modeling: Rigorous applications, better results and higher acceptance. Long range planning 46(1-2): $1-12$.

Hair JF, Ringle CM and Sarstedt M (2011) Partial least squares structural equation modeling. Handbook of market research, 26: 1-40.

Hellier PK, Geursen GM, Carr RA and Rickard JA (2003) Customer repurchase intention. European Journal of Marketing 37: 1762-1800.

Ho DYF (1976) On the Concept of Face. American Journal of Sociology 81(4): 867-884.

Ho LA, Kuo TH and Lin B (2012) How social identification and trust influence organizational online knowledge sharing. Internet Research 22: 4-28.

Hua LY, Ramayah T, Ping TA and Jun-Hwa C (2017) Social media as a tool to help select tourism destinations: The case of Malaysia. Information Systems Management 34(3): 265-279.

Hu LT and Bentler PM (1999) Cutoff criteria for fit indexes in covariance structure analysis: Conventional criteria versus new alternatives. Structural Equation Modeling: A Multidisciplinary Journal 6(1): 1-55.

Huang GB, Mattar M, Berg T and Learned-Miller (2008) Labeled faces in the wild: A database for studying face recognition in unconstrained environments. In: Workshop on Faces in 'Real-Life' Images: Detection, Alignment, and Recognition, Marseille, France, October 2008, pp. 1-14. France: HAL-Inria. 
Hung, K., Xiao, H., \& Yang, X. (2013). Why immigrants travel to their home places: Social capital and acculturation perspective. Tourism Management, 36, 304-313.

Hung SW and Cheng MJ (2013) Are you ready for knowledge sharing? An empirical study of virtual communities. Computers \& Education 62: 8-17.

Hung SY, Lai HM and Chang WW (2011) Knowledge-sharing motivations affecting R\&D employees' acceptance of electronic knowledge repository. Behaviour \& Information Technology 30(2): 213-230.

Kang M and Schuett MA (2013) Determinants of Sharing Travel Experiences in Social Media. Journal of Travel \& Tourism Marketing 30(1-2): 93-107.

Kaplan AM and Haenlein M (2010) Users of the world, unite! The challenges and opportunities of Social Media. Business Horizons 53(1): 59-68.

Kapoor KK, Tamilmani K, Rana NP, Patil P, Dwivedi YK and Nerur S (2018) Advances in social media research: Past, present and future. Information Systems Frontiers 20(3): 531-558.

Kim JH and Cho SE (2013) A study on the relationship between the characteristics of services and repurchase intention in social commerce. Journal of the Korea Service Management Society 14(1): 73-96.

Kim MJ, Lee CK and Bonn M (2016) The effect of social capital and altruism on seniors' revisit intention to social network sites for tourism-related purposes. Tourism Management 53: 96-107.

Kwahk KY and Park DH (2016) The effects of network sharing on knowledge-sharing activities and job performance in enterprise social media environments. Computers in Human Behavior 55: 826-839.

Law R, Bai B, Ritchie JB, Tung VWS and Ritchie RJ (2011) Tourism experience management research. International Journal of Contemporary Hospitality Management 23: 419-438.

Law R, Buhalis D and Cobanoglu C (2014) Progress on information and communication technologies in hospitality and tourism. International Journal of Contemporary Hospitality Management 26: 727-750.

Law R, Leung R, Lo A, Leung D and Fong LHN (2015) Distribution channel in hospitality and tourism. International Journal of Contemporary Hospitality Management 27: 431-452.

Lee CH, Ha BC and Johnston W (2018) The impact of buyer-supplier relationships' social capital 
on bi-directional information sharing in the supply chain. Journal of Business \& Industrial Marketing. 33(3): 325-336.

Lee MR, Yen DC and Hsiao CY (2014) Understanding the perceived community value of Facebook users. Computers in Human Behavior 35: 350-358.

Leem BH, Rogers KJ and Management O (2017) The moderating effect of supply chain role on the relationship between social capital and performance. International Journal of Services and Operations Management 26(1): 18-48.

Leong LY, Hew TS, Ooi KB and Lin B (2019) Do electronic word-of-mouth and elaboration likelihood model influence hotel booking? Journal of Computer Information Systems 59(2):146-160.

Leung D, Law R, Van Hoof H and Buhalis D (2013) Social Media in Tourism and Hospitality: A Literature Review. Journal of Travel \& Tourism Marketing 30(1-2): 3-22.

Leung TKP and Yee-kwong Chan R (2003) Face, favour and positioning - a Chinese power game. European Journal of Marketing 37(11-12): 1575-1598.

Leung XY and Bai B (2013) How Motivation, Opportunity, and Ability Impact Travelers' Social Media Involvement and Revisit Intention. Journal of Travel \& Tourism Marketing 30(12): $58-77$.

Lindell MK and Whitney DJ (2001) Accounting for common method variance in cross-sectional research designs. Journal of Applied Psychology 86(1): 114.

Lin Y (1936) A history of the press and public opinion in China. London: University of Chicago Press.

Liu L, Cheung CMK and Lee MKO (2016) An empirical investigation of information sharing behavior on social commerce sites. International Journal of Information Management 36(5): 686-699.

Magnusson D, Stattin H, Damon W and Lerner RM (1998) Handbook of child psychology: Vol. 1. Theoretical models of human development. John Wiley \& Sons Inc.

MCMC - Malaysian Communications and Multimedia Commission (2019) Internet Users Survey 2019. Report, Putrajaya, Malaysia.

Michaelidou N, Siamagka NT and Christodoulides G (2011) Usage, barriers and measurement of social media marketing: An exploratory investigation of small and medium B2B brands. Industrial Marketing Management 40(7): 1153-1159. 
Mohseni S, Jayashree S, Rezaei S, Kasim A and Okumus F (2018) Attracting tourists to travel companies' websites: The structural relationship between website brand, personal value, shopping experience, perceived risk and purchase intention. Current Issues in Tourism 21(6): 616-645.

Moital M, Vaughan R, Edwards J and Peres R (2009) Determinants of Intention to Purchase Over the Internet. Anatolia 20(2): 345-358.

Nahapiet J and Ghoshal S (1998) Social capital, intellectual capital, and the organizational advantage. Academy of management review 23(2): 242-266.

Oliveira, T., Araujo, B., \& Tam, C. (2020). Why do people share their travel experiences on social media?. Tourism Management, 78, 104041.

Pai P and Tsai HT (2016) Reciprocity norms and information-sharing behavior in online consumption communities: An empirical investigation of antecedents and moderators. Information \& Management 53(1): 38-52.

Podsakoff PM, MacKenzie SB, Lee JY and Podsakoff NP (2003) Common method biases in behavioral research: A critical review of the literature and recommended remedies. Journal of Applied Psychology 88(5): 879-903.

Prasetio A (2014) Understanding knowledge sharing and social capital in social network sites. International Journal of Science and Research 3(3): 760-766.

Reio Jr TG (2010) The threat of common method variance bias to theory building. Human Resource Development Review 9(4): 405-411.

Renny, Guritno S and Siringoringo H (2013) Perceived Usefulness, Ease of Use, and Attitude Towards Online Shopping Usefulness Towards Online Airlines Ticket Purchase. Procedia - Social and Behavioral Sciences 81: 212-216.

Rezaei S, Shahijan MK, Valaei N, Rahimi R and Ismail WKW (2018) Experienced international business traveller's behaviour in Iran: A partial least squares path modelling analysis. Tourism and Hospitality Research 18(2): 163-190.

Ringle CM, Wende S and Becker J. (2015) SmartPLS 3. Available at: http://www. smartpls. com. (Accessed 02 May 2019).

Rottman JW (2008) Successful knowledge transfer within offshore supplier networks: A case study exploring social capital in strategic alliances. Journal of Information Technology 23(1): 31-43. 
Ryan RM and Deci EL (2001) On happiness and human potentials: A review of research on hedonic and eudaimonic well-being. Annual Review of Psychology 52: 141-166.

Sarstedt M, Henseler J and Ringle C (2011) Multi-group analysis in partial least square (PLS) path modeling: Alternative methods and empirical results. Advances in International Marketing 22: $195-218$.

Tohidinia Z and Mosakhani M (2010) Knowledge sharing behaviour and its predictors. Industrial Management \& Data Systems 110: 611-631.

Valenzuela S, Park N and Kee KF (2009) Is There Social Capital in a Social Network Site?: Facebook Use and College Students' Life Satisfaction, Trust, and Participation. Journal of Computer-Mediated Communication 14: 875-901.

VM 2020 - Visit Malaysia (2020) Visit Malaysia Year. Available from: https://www.tourism.gov.my/campaigns/view/visit-malaysia-year [Accessed 20 February 2020].

Wang CY and Wu LW (2011) Reference Effects on Revisit Intention: Involvement as a Moderator. Journal of Travel \& Tourism Marketing 28: 817-827.

Wang X, Huang Y, Li X and Peng L (2016) A Moderated Mediation Model of Sharing Travel Experience on Social Media: Motivations and Face Orientations in Chinese Culture. Journal of China Tourism Research 12(1): 42-64.

Yang X and Li G (2016) Factors influencing the popularity of customer-generated content in a company-hosted online co-creation community: A social capital perspective. Computers in Human Behavior 64: 760-768.

Yuan D, Lin Z and Zhuo R (2016) What drives consumer knowledge sharing in online travel communities?: Personal attributes or e-service factors? Computers in Human Behavior 63: 68-74.

Zhang XA, Cao Q and Grigoriou N (2011) Consciousness of Social Face: the development and validation of a scale measuring desire to gain face versus fear of losing face. J Soc Psychol 151: 129-149.

Zheng $\mathrm{H}, \mathrm{Li} \mathrm{D}, \mathrm{Wu} \mathrm{J}$ and $\mathrm{Xu} \mathrm{Y} \mathrm{(2014)} \mathrm{The} \mathrm{role} \mathrm{of} \mathrm{multidimensional} \mathrm{social} \mathrm{capital} \mathrm{in}$ crowdfunding: A comparative study in China and US. Information \& Management 51(4): $488-496$. 
Figure 1: Proposed model

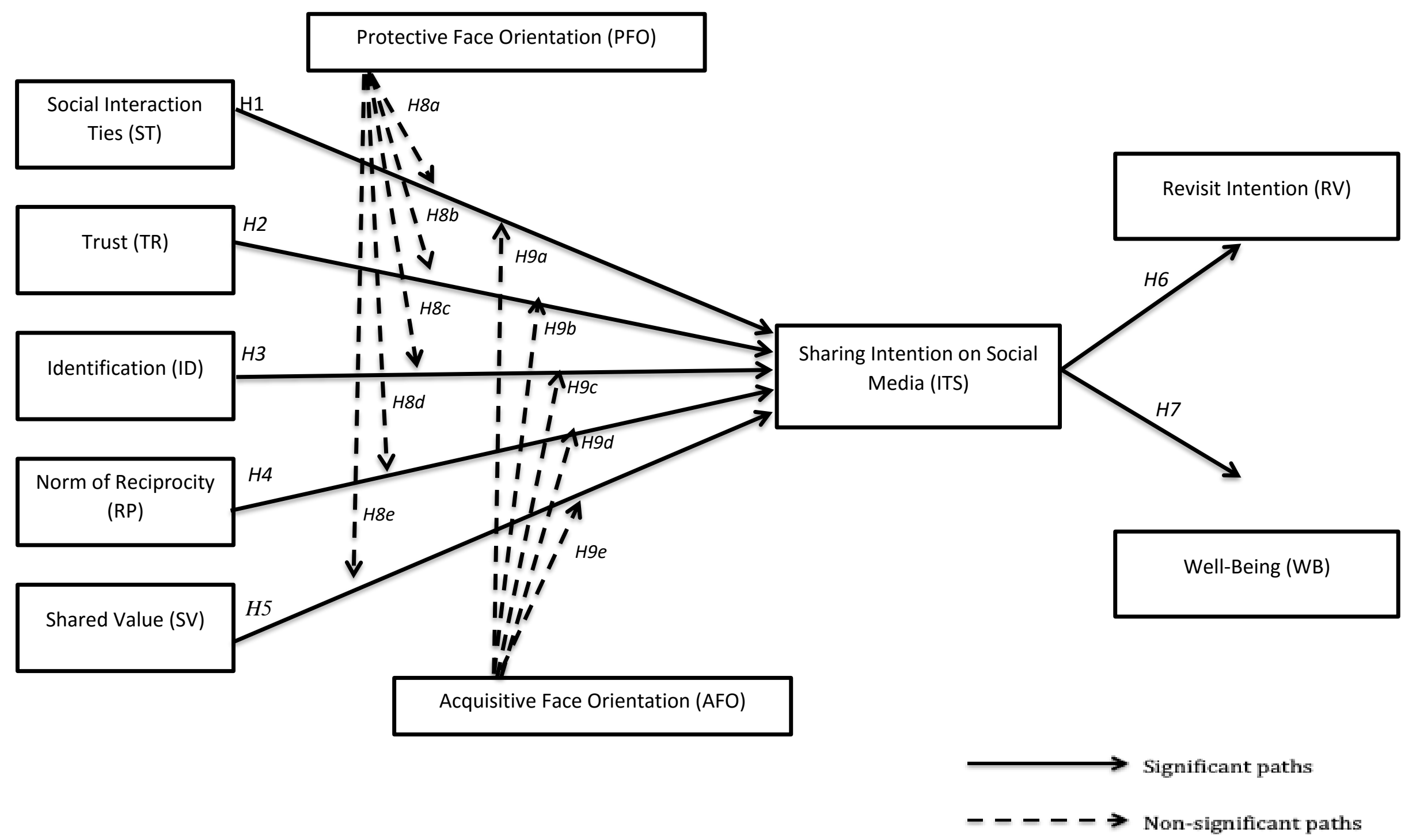


Figure 2: SEM analysis results of proposed model

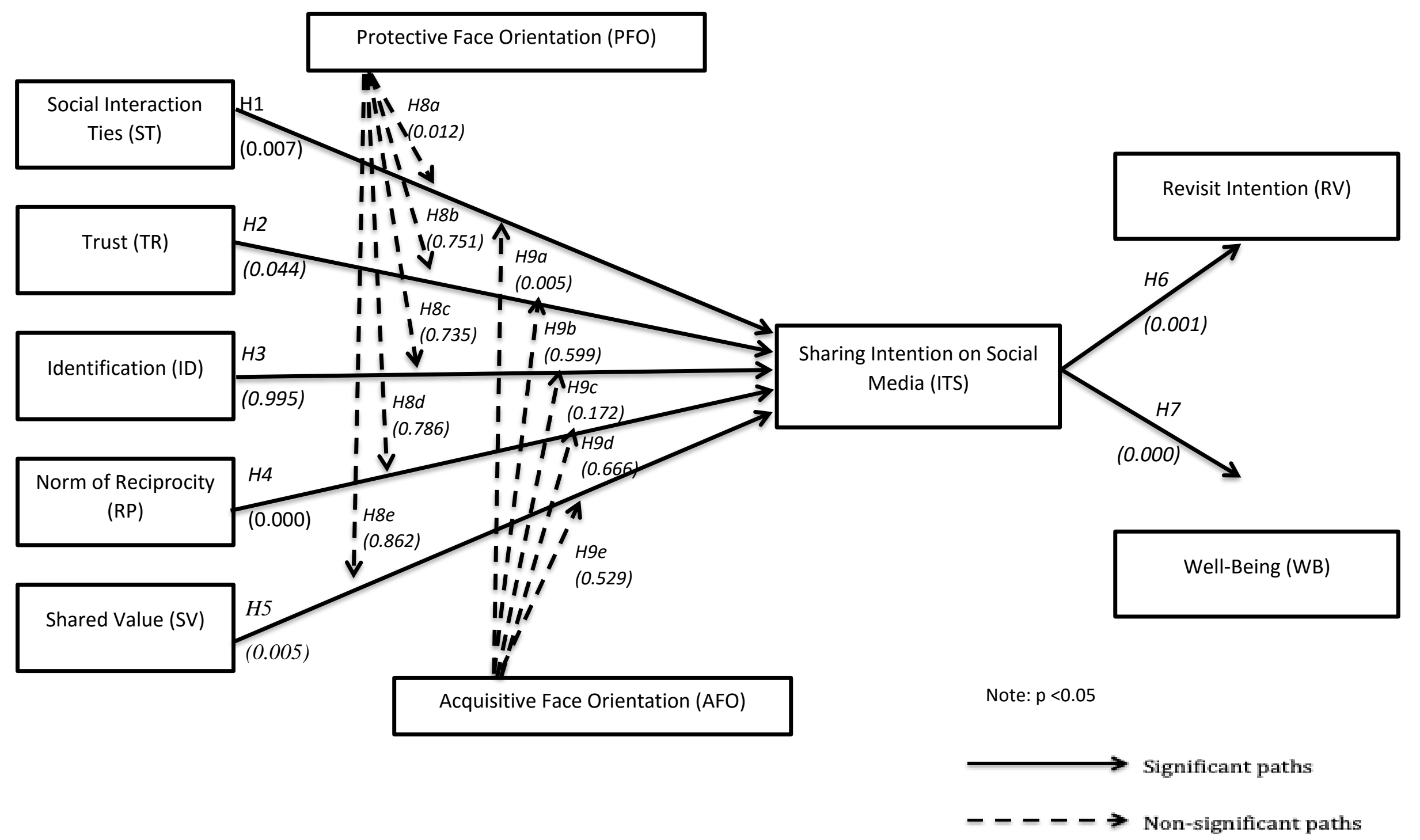


Table 1: Demographic statistics of the sample data

\begin{tabular}{|c|c|c|c|}
\hline Measure & Items & $\begin{array}{c}\text { Number of } \\
\text { Respondents ( } n \text { ) }\end{array}$ & $\begin{array}{c}\text { Percentage } \\
\text { (\%) }\end{array}$ \\
\hline \multirow[t]{2}{*}{ Gender } & Female & 269 & 63.6 \\
\hline & Male & 154 & 36.4 \\
\hline \multirow[t]{6}{*}{ Age } & Below 19 years & 10 & 2.4 \\
\hline & $19-29$ years & 321 & 75.9 \\
\hline & $30-39$ years & 50 & 11.8 \\
\hline & $40-49$ years & 26 & 6.1 \\
\hline & 50 - 59 years & 16 & 3.8 \\
\hline & 60 years above & 0 & 0 \\
\hline \multirow[t]{3}{*}{ Education Level } & High School & 16 & 3.8 \\
\hline & Undergraduate & 344 & 81.3 \\
\hline & Postgraduate & 63 & 14.9 \\
\hline \multirow[t]{5}{*}{ Occupation } & Student & 274 & 64.8 \\
\hline & Working & 140 & 33.1 \\
\hline & Retiree & 0 & 0 \\
\hline & Home Maker & 5 & 1.2 \\
\hline & Others & 4 & 0.9 \\
\hline \multirow[t]{5}{*}{ Most used SNS } & Facebook & 289 & 68.3 \\
\hline & Twitter & 27 & 6.4 \\
\hline & Instagram & 100 & 23.6 \\
\hline & Pinterest & 2 & 0.5 \\
\hline & Other & 5 & 1.2 \\
\hline \multirow[t]{3}{*}{ Using SNS since } & Less than 1 year & 18 & 4.3 \\
\hline & $1-2$ years & 45 & 10.6 \\
\hline & $3-4$ years & 138 & 32.6 \\
\hline
\end{tabular}




\begin{tabular}{|llcc|}
\hline & More than 5 years & 222 & 52.5 \\
\hline Hours spend per day & Less than 1 hour & 103 & 24.3 \\
\hline $1-4$ hours & 256 & 60.5 \\
\hline $5-8$ hours & 56 & 13.2 \\
\hline Frequency of visiting SNS & Everyday & 8 & 1.9 \\
\hline & $2-3$ times a week & 342 & 80.9 \\
\hline & Weekly & 21 & 11.3 \\
\hline Monthly & 4 & 5.0 \\
\hline Rarely & 8 & 0.9 \\
\hline Fo of Contacts & Fewer than 100 & 96 & 22.7 \\
\hline & $100-200$ & 107 & 25.3 \\
\hline $300-400$ & 74 & 17.5 \\
\hline & More than 400 & 146 & 34.5 \\
\hline
\end{tabular}


Table 2: Construct loadings

\begin{tabular}{|c|c|c|c|}
\hline Construct & Measurement items & $\lambda$ & t-value \\
\hline \multicolumn{4}{|l|}{ Social Capital } \\
\hline \multirow[t]{3}{*}{$\begin{array}{l}\text { Structural - } \\
\text { Social Ties }\end{array}$} & $\begin{array}{l}\text { ST1: I maintain close social relationships with } \\
\text { some members on SNSs. }\end{array}$ & 0.888 & 81.963 \\
\hline & $\begin{array}{l}\text { ST2: I spend a lot of time interacting with } \\
\text { some members on SNSs. }\end{array}$ & 0.908 & 94.732 \\
\hline & $\begin{array}{l}\text { ST4: I have frequent communication with } \\
\text { some members on SNSs. }\end{array}$ & 0.919 & 112.892 \\
\hline \multirow[t]{4}{*}{ Relational - Trust } & $\begin{array}{l}\text { TR1: I can always trust members on SNSs to } \\
\text { lend me a hand if I need it. }\end{array}$ & 0.931 & 151.636 \\
\hline & $\begin{array}{l}\text { TR2: When faced with difficulties, members on } \\
\text { SNS would help me to overcome the problem. }\end{array}$ & 0.934 & 113.810 \\
\hline & $\begin{array}{l}\text { TR3: Members I know on SNSs will not take } \\
\text { advantage of others when the opportunity } \\
\text { arises. }\end{array}$ & 0.893 & 40.535 \\
\hline & $\begin{array}{l}\text { TR4: I know members on SNSs will always keep } \\
\text { the promises they make to one another. }\end{array}$ & 0.894 & 50.776 \\
\hline \multirow[t]{3}{*}{ Reciprocity } & RP1: It is fair to help other members on SNSs. & 0.868 & 41.031 \\
\hline & $\begin{array}{l}\text { RP2: I know that members on SNSs will help } \\
\text { me, so it's only fair to help other members. }\end{array}$ & 0.944 & 138.141 \\
\hline & $\begin{array}{l}\text { RP3: I believe that members on SNSs would } \\
\text { help me if I need it. }\end{array}$ & 0.915 & 54.874 \\
\hline \multirow[t]{2}{*}{ Identification } & ID1: I feel a sense of belonging towards SNSs. & 0.920 & 81.286 \\
\hline & $\begin{array}{l}\text { ID2: I have the feeling of togetherness or } \\
\text { closeness towards the members on SNSs. }\end{array}$ & 0.935 & 80.976 \\
\hline
\end{tabular}




\begin{tabular}{|c|c|c|c|}
\hline & $\begin{array}{l}\text { ID3: I have a strong positive feeling towards } \\
\text { SNSs. }\end{array}$ & 0.936 & 116.438 \\
\hline \multirow[t]{4}{*}{$\begin{array}{l}\text { Cognitive - } \\
\text { Shared Vision }\end{array}$} & $\begin{array}{l}\text { SV1: Members on the SNSs share the vision of } \\
\text { helping others solve their problems. }\end{array}$ & 0.915 & 80.753 \\
\hline & $\begin{array}{l}\text { SV2: Members on the SNSs share the same } \\
\text { goal of learning from each other. }\end{array}$ & 0.909 & 65.440 \\
\hline & $\begin{array}{l}\text { SV3: Members on SNSs use understandable } \\
\text { communication patterns during discussions. }\end{array}$ & 0.933 & 106.846 \\
\hline & $\begin{array}{l}\text { SV4: Members on SNSs use understandable } \\
\text { narrative forms to post. }\end{array}$ & 0.917 & 64.176 \\
\hline \multirow[t]{4}{*}{$\begin{array}{l}\text { Intention to } \\
\text { share }\end{array}$} & $\begin{array}{l}\text { ITS1: I will upload my opinion about Beach } \\
\text { Resort X on SNSs. }\end{array}$ & 0.952 & 102.108 \\
\hline & $\begin{array}{l}\text { ITS2: I will share my reviews about Beach } \\
\text { Resort X on SNSs. }\end{array}$ & 0.978 & 396.508 \\
\hline & $\begin{array}{l}\text { ITS3: On SNSs, I will inform friends about } \\
\text { Beach Resort X experience. }\end{array}$ & 0.905 & 58.359 \\
\hline & $\begin{array}{l}\text { ITS4: I will post information on Beach Resort X } \\
\text { on SNSs. }\end{array}$ & 0.951 & 124.228 \\
\hline \multirow[t]{2}{*}{ Revisit Intention } & $\begin{array}{l}\text { RV2: I consider this resort to be my first choice } \\
\text { for future travel destination. }\end{array}$ & 0.995 & 90.445 \\
\hline & $\begin{array}{l}\text { RV3: I would keep doing business with this } \\
\text { resort in the future. }\end{array}$ & 0.993 & 54.324 \\
\hline \multirow[t]{3}{*}{ Well-being } & $\begin{array}{l}\text { WB1: In most respects, my opinion shared on } \\
\text { SNSs is close to my ideal. }\end{array}$ & 0.908 & 74.754 \\
\hline & $\begin{array}{l}\text { WB2: The conditions of my opinion shared on } \\
\text { SNSs are excellent. }\end{array}$ & 0.890 & 47.279 \\
\hline & $\begin{array}{l}\text { WB3: It is my duty to post or share about } \\
\text { satisfactory experiences with Beach Resort X. }\end{array}$ & 0.892 & 47.133 \\
\hline
\end{tabular}




\begin{tabular}{|c|c|c|c|}
\hline & $\begin{array}{l}\text { WB4: I am satisfied with my opinion shared } \\
\text { on SNSs. }\end{array}$ & 0.931 & 120.865 \\
\hline \multicolumn{4}{|l|}{ Face Orientation } \\
\hline \multirow[t]{5}{*}{$\begin{array}{l}\text { Protective Face } \\
\text { Orientation }\end{array}$} & $\begin{array}{l}\text { PFO1: I do my best to hide my weakness in } \\
\text { front of others. }\end{array}$ & 0.823 & 35.212 \\
\hline & $\begin{array}{l}\text { PFO2: I prefer to maintain a minimum of my } \\
\text { dignity rather than to gain face. }\end{array}$ & 0.857 & 41.007 \\
\hline & $\begin{array}{l}\text { PFO4: I don't like to talk a lot so as to avoid } \\
\text { attracting others' attention. }\end{array}$ & 0.731 & 13.946 \\
\hline & $\begin{array}{l}\text { PFO5: I seem to be more fearful of losing face } \\
\text { than others. }\end{array}$ & 0.792 & 32.286 \\
\hline & $\begin{array}{l}\text { PFO6: I seem to be conservative and less self- } \\
\text { promoting when talking to others. }\end{array}$ & 0.804 & 21.140 \\
\hline \multirow[t]{5}{*}{$\begin{array}{l}\text { Acquisitive Face } \\
\text { Orientation }\end{array}$} & AFO2: I am happy to show my bright side. & 0.903 & 87.121 \\
\hline & $\begin{array}{l}\text { AFO3: I hope that, in the eyes of others, I have } \\
\text { a better life than most people. }\end{array}$ & 0.871 & 45.765 \\
\hline & $\begin{array}{l}\text { AFO4: Praise and admiration are important to } \\
\text { me. }\end{array}$ & 0.873 & 47.854 \\
\hline & AFO5: I like to talk about new topics. & 0.890 & 76.818 \\
\hline & $\begin{array}{l}\text { AFO6: I will seize any opportunity to show } \\
\text { myself off to gain face. }\end{array}$ & 0.875 & 62.466 \\
\hline
\end{tabular}

Notes: $\lambda$ - first order factor loadings, all $t$-values $>1.96$ are significant at $p<0.05$. 
Table 3: Cronbach coefficient alpha ( $\alpha)$, Composite reliability,

Average variance extracted (AVE)

\begin{tabular}{|c|c|c|c|c|}
\hline Construct & Items & $\begin{array}{c}\text { Cronbach's } \\
\qquad \alpha\end{array}$ & $\begin{array}{l}\text { Composite } \\
\text { Reliability }\end{array}$ & $\begin{array}{c}\text { Average } \\
\text { Variance } \\
\text { Extracted (AVE) }\end{array}$ \\
\hline Social Capital & & & & \\
\hline Structural & Social Ties & 0.890 & 0.931 & 0.819 \\
\hline Relational & Trust & 0.934 & 0.953 & 0.834 \\
\hline & Identification & 0.923 & 0.951 & 0.866 \\
\hline & Reciprocity & 0.895 & 0.935 & 0.827 \\
\hline Cognitive & Shared Value & 0.938 & 0.956 & 0.844 \\
\hline $\begin{array}{l}\text { Intention to } \\
\text { Share }\end{array}$ & & 0.961 & 0.972 & 0.896 \\
\hline Well-being & & 0.926 & 0.948 & 0.819 \\
\hline Revisit Intention & & 0.987 & 0.994 & 0.987 \\
\hline $\begin{array}{l}\text { Face } \\
\text { Orientation }\end{array}$ & Protective & 0.866 & 0.900 & 0.644 \\
\hline & Acquisitive & 0.929 & 0.946 & 0.779 \\
\hline
\end{tabular}


Table 4: Discriminant validity of latent constructs: Fornell-Larcker criterion

\begin{tabular}{|c|c|c|c|c|c|c|c|c|c|c|c|}
\hline & 1 & 2 & 3 & 4 & 5 & 6 & 7 & 8 & 9 & 10 & 11 \\
\hline (1) AFO & 0.883 & & & & & & & & & & \\
\hline (2) Identification & 0.478 & 0.93 & & & & & & & & & \\
\hline $\begin{array}{l}\text { (3) Intention } \\
\text { to share }\end{array}$ & 0.425 & 0.597 & 0.947 & & & & & & & & \\
\hline (4) PFO & 0.726 & 0.384 & 0.33 & 0.798 & & & & & & & \\
\hline (5) Reciprocity & 0.459 & 0.712 & 0.686 & 0.399 & 0.909 & & & & & & \\
\hline (6) Revisit & 0.059 & 0.096 & 0.086 & 0.104 & 0.04 & 0.994 & & & & & \\
\hline (7) Marker & -0.011 & 0.04 & -0.094 & 0.008 & 0.011 & -0.034 & 1 & & & & \\
\hline (8) Shared Vision & 0.498 & 0.792 & 0.632 & 0.422 & 0.742 & 0.029 & 0.024 & 0.919 & & & \\
\hline (9) Social Ties & 0.481 & 0.722 & 0.584 & 0.427 & 0.685 & 0.113 & -0.025 & 0.57 & 0.905 & & \\
\hline (10) Trust & 0.358 & 0.629 & 0.55 & 0.311 & 0.66 & 0.143 & -0.097 & 0.635 & 0.568 & 0.913 & \\
\hline (11) Well-Being & 0.527 & 0.535 & 0.77 & 0.45 & 0.568 & 0.152 & -0.025 & 0.614 & 0.513 & 0.53 & 0.905 \\
\hline $\begin{array}{l}\text { Variance } \\
\text { Inflation Factor }\end{array}$ & 4.463 & 4.13 & 1.008 & 4.668 & 4.282 & DV & - & 3.956 & 2.927 & 2.793 & DV \\
\hline
\end{tabular}

Note: Diagonals represent the average variance extracted (AVE) while the other entries represent the squared correlations. 
Table 5: Structural model results

\begin{tabular}{|c|c|c|c|}
\hline Path & $\boldsymbol{\beta}$ & t-value & p-value \\
\hline \multicolumn{4}{|l|}{ Direct Path } \\
\hline $\mathrm{ST} \rightarrow \mathrm{ITS}$ & 0.161 & 2.688 & 0.007 \\
\hline $\mathrm{TR} \rightarrow \mathrm{ITS}$ & 0.121 & 2.021 & 0.044 \\
\hline $\mathrm{RC} \rightarrow \mathrm{ITS}$ & 0.330 & 4.742 & 0.000 \\
\hline ID $\rightarrow$ ITS & 0.003 & 0.006 & 0.995 \\
\hline$S V \rightarrow$ ITS & 0.209 & 2.806 & 0.005 \\
\hline ITS $\rightarrow$ WB & 0.773 & 31.414 & 0.000 \\
\hline ITS $\rightarrow$ RI & 0.167 & 3.303 & 0.001 \\
\hline \multicolumn{4}{|l|}{ Indirect Paths } \\
\hline $\mathrm{ST} \rightarrow \mathrm{ITS} \rightarrow \mathrm{RI}$ & 0.029 & 1.976 & 0.049 \\
\hline $\mathrm{TR} \rightarrow \mathrm{ITS} \rightarrow \mathrm{RI}$ & 0.074 & 2.023 & 0.044 \\
\hline ID $\rightarrow$ ITS $\rightarrow$ RI & 0.001 & 0.078 & 0.938 \\
\hline $\mathrm{RC} \rightarrow \mathrm{ITS} \rightarrow \mathrm{RI}$ & 0.059 & 2.743 & 0.006 \\
\hline $\mathrm{SV} \rightarrow \mathrm{ITS} \rightarrow \mathrm{RI}$ & 0.005 & 1.983 & 0.048 \\
\hline $\mathrm{ST} \rightarrow \mathrm{ITS} \rightarrow \mathrm{WB}$ & 0.125 & 2.691 & 0.007 \\
\hline $\mathrm{TR} \rightarrow \mathrm{ITS} \rightarrow \mathrm{WB}$ & 0.093 & 2.003 & 0.046 \\
\hline ID $\rightarrow$ ITS $\rightarrow$ WB & 0.002 & 0.006 & 0.995 \\
\hline $\mathrm{RC} \rightarrow \mathrm{ITS} \rightarrow \mathrm{WB}$ & 0.255 & 4.704 & 0.000 \\
\hline SV $\rightarrow$ ITS $\rightarrow$ WB & 0.162 & 2.805 & 0.005 \\
\hline \multicolumn{4}{|l|}{ Moderation Paths } \\
\hline ST $\rightarrow$ PFO $\rightarrow$ ITS & -0.347 & 2.540 & 0.012 \\
\hline $\mathrm{TR} \rightarrow \mathrm{PFO} \rightarrow \mathrm{ITS}$ & 0.023 & 0.317 & 0.751 \\
\hline
\end{tabular}




\begin{tabular}{|lccc|}
\hline ID $\rightarrow$ PFO $\rightarrow$ ITS & -0.061 & 0.339 & 0.735 \\
\hline RC $\rightarrow$ PFO $\rightarrow$ ITS & 0.043 & 0.272 & 0.786 \\
\hline SV $\rightarrow$ PFO $\rightarrow$ ITS & -0.027 & 0.174 & 0.862 \\
\hline ST $\rightarrow$ AFO $\rightarrow$ ITS & 0.353 & 2.831 & 0.005 \\
\hline TR $\rightarrow$ AFO $\rightarrow$ ITS & -0.047 & 0.527 & 0.599 \\
\hline ID $\rightarrow$ AFO $\rightarrow$ ITS & 0.237 & 1.367 & 0.172 \\
\hline RC $\rightarrow$ AFO $\rightarrow$ ITS & 0.069 & 0.433 & 0.666 \\
\hline SV $\rightarrow$ AFO $\rightarrow$ ITS & -0.102 & 0.630 & 0.529 \\
\hline
\end{tabular}

Note: All t-values $>1.96$ are significant at $p<0.05$. 
Table 6: Summary of results

\begin{tabular}{|l|l|l|}
\hline \multicolumn{2}{|l|}{ Hypothesis } & Inference \\
\hline H1 & $\begin{array}{l}\text { Social interaction ties impact sharing intentions } \\
\text { on social media. }\end{array}$ & Supported \\
\hline H2 & $\begin{array}{l}\text { Trust impacts sharing intentions on social } \\
\text { media. }\end{array}$ & Supported \\
\hline H3 & $\begin{array}{l}\text { Identification impacts sharing intention on } \\
\text { social media. }\end{array}$ & Not Supported \\
\hline H4 & $\begin{array}{l}\text { Norm of reciprocity impacts sharing intentions } \\
\text { on social media. }\end{array}$ & Supported \\
\hline H5 & $\begin{array}{l}\text { Shared vision and language impacts sharing } \\
\text { intentions on social media. }\end{array}$ & Supported \\
\hline H6 & $\begin{array}{l}\text { Sharing intentions on social media have a } \\
\text { positive impact on revisit intention. }\end{array}$ & Supported \\
\hline H8a & $\begin{array}{l}\text { Sharing intentions on social media have a } \\
\text { positive impact on well-being. }\end{array}$ & Supported \\
\hline influences social capital dimensions and & Partially Supported \\
\hline intention. & \\
\hline
\end{tabular}

